\title{
Oxidised regenerated cellulose as a cause of paraplegia after thoracotomy: case report and review of the literature
}

\author{
S Dogan*, ${ }^{*}$ H Kocaeli ${ }^{1}$ and M Doygun ${ }^{1}$ \\ ${ }^{1}$ Department of Neurosurgery, School of Medicine, Uludă University, Bursa, Turkey
}

Study design: Case report.

Objective: To report an unusual case of paraplegia.

Setting: University Hospital Bursa, Turkey.

Case report: A 22-year-old woman presented with paraplegia following a left-sided thoracotomy. Magnetic resonance imaging showed a dorsal epidural mass at the level of T6. The patient underwent an emergency T6/7 laminectomy and removal of a tuft of oxidised regenerated cellulose, which had migrated through the intervertebral foramen causing spinal cord compression.

Conclusion: In cases of neurological deficits after surgery at the posterolateral edge of a thoracotomy, the clinician should be aware of the above possibility. Urgent radiological diagnosis and decompressive laminectomy is the treatment of choice.

Spinal Cord (2005) 43, 445-447. doi:10.1038/sj.sc.3101632; Published online 17 May 2005

Keywords: oxidised regenerated cellulose; paraplegia; spinal cord compression; thoracotomy

\section{Introduction}

Paraplegia following nonspinal surgery is a rare complication that has been reported after surgery of the thoracic or abdominal aorta, ${ }^{1-3}$ pulmonary surgery, ${ }^{4}$ and epidural catheterisation. ${ }^{5}$ Oxidised regenerated cellulose (ORC) is a commonly used haemostatic agent in various surgical diciplines that gradually increases in volume following saturation with blood. ${ }^{6,7}$ We report a case of paraplegia following thoracic surgery during which ORC had been placed in the posterior angle of thoracotomy incision for controlling haemorrhage. We also discuss 13 reports found in the literature of postthoracotomy paraplegia due to ORC.

\section{Case report}

\section{History and examination}

A 22-year-old woman presented with a history of paraplegia $36 \mathrm{~h}$ following a left-sided thoracotomy at another institution. On admission, neurological examination indicated that she was able to move her right leg when gravity was eliminated but had a left leg flaccid monoplegia with loss of the deep tendon reflexes, urinary incontinence and an extensor plantar response. There was hypoesthesia below the level of T4. Magnetic resonance imaging (MRI) of the thoracic spine revealed

*Correspondence: S Dogan, Department of Neurosurgery, School of Medicine, Uludağ University, Gorukle, 16059 Bursa, Turkey a dorsal epidural mass lesion at the level of the T6 vertebrae. The lesion was dumbell shaped and was located both inside and outside the spinal canal (Figure $1 \mathrm{a}$ and $\mathrm{b}$ ); it appeared isointense to slightly hyperintense and markedly hypointense on T1- and T2-weighted images, respectively, and did not enhance after contrast administration. The signal characteristics were consistent with early acute-subacute haemorrhage.

\section{Operation}

An emergency laminectomy of T6 and T7 vertebrae revealed an epidural compressing mass lesion that was found to have migrated through the intervertebral foramen. The mass, which turned out to be a hard tuft of ORC (Surgicel ${ }^{\circledR}$, Ethicon, Switzerland), was removed and the spinal cord decompressed. The dural sac then expanded and pulsated normally.

\section{Postoperative course}

By the sixth postoperative month, the patient had experienced a gradual return of power of the right leg against gravity, unfortunately the left leg remained paralysed.

\section{Discussion}

Paraplegia after thoracic aortic surgery is a relatively frequent complication that is generally considered to 


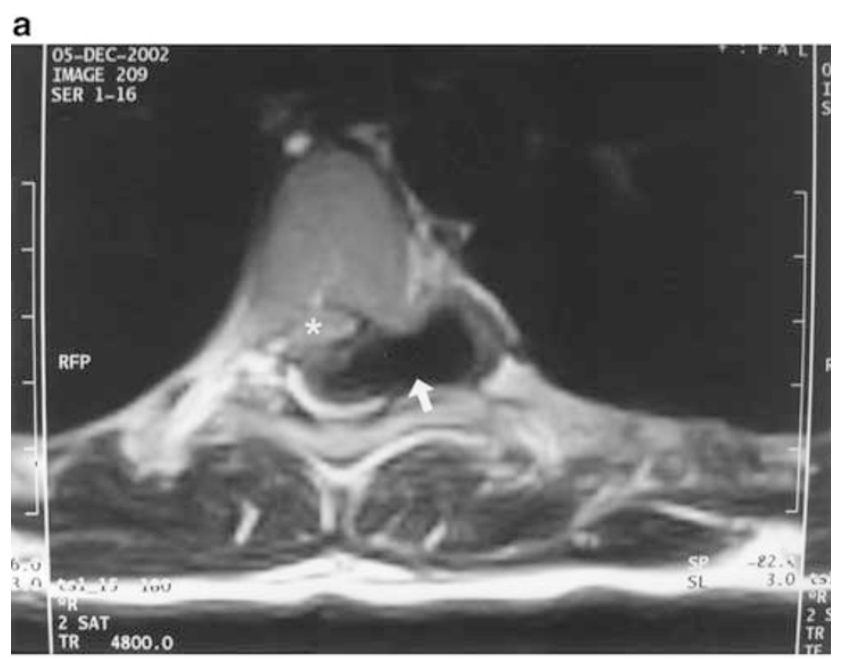

b

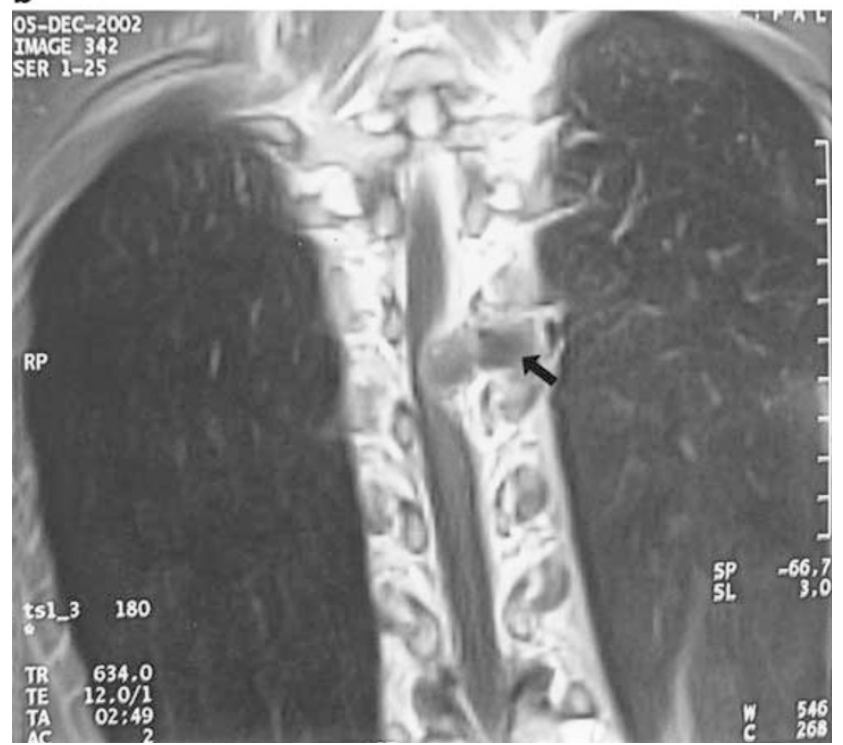

Figure 1 (a) Axial T2-weighted MR image of the thoracic spine showing a dumbbell-shaped compressive mass lesion that has hypointense appearance (arrow), displacing the cord anteriolaterally (asterisk). (b) Coronal T1-weighted contrastenhanced MR image which shows a hypointense unenhancing lesion causing marked compression of the spinal cord (arrow)

be the result of compromise of spinal cord blood flow during aortic crossclamping or after ligation of the posterior intercostal arteries. ${ }^{6,8}$ On the other hand, paraplegia after thoracotomy is an extremely uncommon complication, with an estimated incidence of $0.08 \%{ }^{6}$ The common denominator of paraplegia complicating thoracotomy is a posterolateral thoracotomy incision. The more posterior the incision is toward the vertebrae, the greater the chance of injury of the spinal cord. ${ }^{6}$ Bleeding at the costovertebral angle is another common feature of these cases. Manoeuvers aimed at haemostasis at the posterior edge of a posterolateral thoracotomy such as packing the wound with haemostatic agents or electrocauterisation could create a pleural epidural or even a pleural subarachnoidal communication through the intervertebral foramen. ${ }^{4,9}$ In the presence of an intact pleura, the epidural space has no communication with the pleural cavitiy. The distance that separates the pleural cavitiy posteriorly from the spinal canal and the dura through the intervertebral foramina is very short and the intervertebral foramine do not form a strong barrier protecting the spinal cord. ${ }^{10,11}$

Use of ORC as a haemostatic agent is common in neurosurgery, orthopaedic surgery and thoracic surgery. Following saturation with blood, it gradually increases in volume and forms a gelatinous mass that aids in the formation of clot. Pushed or packed through a pleuro-epidural communication, ORC may enter the vertebral canal and directly compress the spinal cord. Also, packed ORC left in place preventing the drainage of active bleeding in the pleural cavitiy, may swell and promote haematoma formation inside the vertebral canal, with consequent spinal cord compression. In 13 previous reports paraplegia due to ORC after pulmonary surgery as in our case have been described; in one case it occured after aortic surgery ${ }^{1}$ (Table 1).

Furthermore, there are reported cases of progressive worsening of paraplegia despite normal neurological status in the early postoperative period. This type of late neurological worsening is thought to result from the migration of ORC through the intervertebral foramen due to a relative pressure gradient between the intervertebral foramen and the spinal canal. Such a pressure gradient on the other hand, could be produced either by closure of the thoracotomy with rib approximation or by respiratory movements. ${ }^{7,12}$

MRI is the best investigation in such cases MRI delineates the location of lesion and the degree of cord compression. Hyperacute haematomas appear hypointense or slightly hyperintense on T1-weighted images and have mixed signal intensity on T2-weighted images. Acute haematomas are also isointense on T1-weighted images, but more hypointense on T2-weighted images; chronic haematomas are hyperintense on all sequences. ${ }^{13}$ In their study on the MRI characteristics of ORC, Oto et $a l,{ }^{14}$ reported that ORC has a short relaxation time on T2-weighted images, leading to marked hypointensity in the early postoperative period, and also noted that T2-weighted images were the most useful in detection of ORC. In our case, there was a marked hypointensity on T2-weighted images which was consistent with acute haematoma.

In conclusion, in cases of neurological deficits after extensive surgery at the posterolateral edge of a thoracotomy, the clinician should be aware of the above possibilities including a compressive tuft of ORC. Urgent radiological diagnosis and decompressive laminectomy is required. 
Table 1 Summary of reported cases of post-thoracotomy paraplegia due to ORC

\begin{tabular}{|c|c|c|c|c|}
\hline Authors & $\begin{array}{l}\text { Patient } \\
\text { age } \\
\text { (years) }\end{array}$ & Operation & $\begin{array}{l}\text { Neurologic } \\
\text { level }\end{array}$ & Outcome \\
\hline Perez-Guera and Hotland ${ }^{9}$ & 59 & Left pneumonectomy & T5 & Paraplegia; no improvement \\
\hline Tashiro et $a l^{10}$ & 56 & $\begin{array}{l}\text { Right upper pulmonary } \\
\text { lobectomy }\end{array}$ & T5 & $\begin{array}{l}\text { Brown-Squard Syndrome } \\
\text { improvement }\end{array}$ \\
\hline Short ${ }^{15}$ & 49 & $\begin{array}{l}\text { Right upper pulmonary } \\
\text { lobectomy }\end{array}$ & T5-6 & $\begin{array}{l}\text { Left leg improved, right } \\
\text { monoplegia }\end{array}$ \\
\hline Short ${ }^{15}$ & 59 & Right lower lobectomy & T5-6 & Paraplegia \\
\hline Short ${ }^{15}$ & 72 & $\begin{array}{l}\text { Right upper and middle } \\
\text { lobectomy }\end{array}$ & T5-6 & Paraplegia \\
\hline Wada et $a l^{12}$ & 37 & Right upper lobectomy & T5 & Improved \\
\hline Wada et $a l^{12}$ & 69 & Right upper lobectomy & T5 & Improved \\
\hline Iwabuchi $^{16}$ & 46 & Right lower lobectomy & T5 & Paraparesis \\
\hline Lovstad et $a l^{17}$ & 56 & Left lower lobectomy & $\mathrm{T} 8$ & Paraplegia \\
\hline Brodbelt et $a l^{7}$ & 15 & $\begin{array}{l}\text { Ventriculoseptal defect } \\
\text { and pulmonary artery } \\
\text { stenosis }\end{array}$ & T5-6 & Paraparesis \\
\hline Brodbelt et $a l^{7}$ & 37 & Lower lobectomy & T5 & Died \\
\hline Brodbelt et $a l^{7}$ & 50 & Thoracic crush injury & NR & Right leg monoparesis \\
\hline Biglioli et $a l^{1}$ & 38 & $\begin{array}{l}\text { Thoracic aortic } \\
\text { aneurysm }\end{array}$ & T6 & Paraplegia \\
\hline Present case & 22 & Left thoracotomy & T6 & $\begin{array}{l}\text { Right leg partially improved, left } \\
\text { monoplegia }\end{array}$ \\
\hline
\end{tabular}

NR: no record

\section{References}

1 Biglioli B, Roberto M, Cannata A, Parolari A, Spirito R. Paraplegia after iatrogenic extrinsic spinal cord compression after descending thoracic aorta repair: case report and literature review. J Thorac Cardiovasc Surg 2002; 124: 407-410.

2 Cowley RA, Turney SZ, Hankins JR, Attar S, Shankar B. Rupture of the thoracic aorta due to blunt trauma. $J$ Thorac Cardiovasc Surg 1990; 100: 652-661.

3 Szilagy DE, Hezeman JH, Smith RE, Elliott JP. Spinal cord damage in surgery of abdominal aortic aneurysms. Surgery 1978; 83: 38-56.

4 Batellier J, Wihlm JM, Morand G, Witz JP. Paraplegia due to spinal extradural haematoma after radical pulmonary lobectomy for cancer. Ann Chir 1989; 43: 210-214.

5 Wulf H. Epidural anesthesia and spinal haematoma. Can $J$ Anaesth 1996; 43: 1260-1271.

6 Attar S, Hankins JR, Turney SZ, Krasna MJ, McLaughlin JS. Paraplegia after thoracotomy: report of five cases and review of the literature. Ann Thorac Surg 1995; 59: 1410-1416.

7 Brodbelt AR, Miles JB, Foy PM, Broome JC. Intraspinal oxidised cellulose (Surgicel) causing delayed paraplegia after thoracotomy - a report of three cases. Ann $R$ Coll Surg Engl 2002; 84: 97-99.

8 Mauney MC, Blackbourne LH, Langenburg SE, Buchanan SA, Kron IL, Tribble CG. Prevention of spinal cord injury after repair of the thoracic or thoracoabdominal aorta. Ann Thorac Surg 1995; 59: 245-252.
9 Perez-Guerra F, Holland JM. Epidural hematoma as a cause of postpneumonectomy paraplegia. Ann Thorac Surg 1984; 39: 282.

10 Tashiro C, Iwasaki M, Nakahara K, Yoshiya I. Postoperative paraplegia associated with epidural narcotic administration. Can J Anesth 1987; 34: 190-192.

11 Walker WE. Paraplegia associated with thoracotomy. Ann Thorac Surg 1990; 50: 288-289.

12 Wada E, Yonenobu K, Ebara S, Kuwahara O, Ono K. Epidural migration of hemostatic agents as a cause of postthoracotomy paraplegia: report of two cases. $J$ Neurosurg 1993; 78: 658-660.

13 Felber $\mathrm{S}$ et al. Magnetic resonance tomography in epidural and subdural spinal hematoma. Radiologie 1994; 34: 656-661.

14 Oto A, Remer EM, O’Malley CM, Tkach JA, Gill IS. MR charascteristics of oxidized cellulose (Surgicel). Am J Roentgenol 1999; 172: 1481-1484.

15 Short HD. Paraplegia associated with the use of oxidised cellulose in posterolateral thoracotomy incisions. Ann Thorac Surg 1990; 50: 288-290.

16 Iwabuchi S, Koike K, Okabe T, Tago S, Murakami T. Latrogenic paraplegia caused by surgicel used for hemostasis during a thoracotomy: report of a case. Surg Today 1997; 27: 969-970.

17 Lovstad RZ, Steen PA, Forsman M. Paraplegia after thoracotomy - not caused by the epidural catheter. Acta Anesthesiol Scand 1999; 43: 230-232. 